\title{
Dynamical Characteristics of a Head Expander for Vibration Testing In Pustekbang Laboratory
}

\author{
Nur Mufidatul Ula ${ }^{1, *}$, Yusuf Giri Wijaya ${ }^{2}$, Muksin ${ }^{3}$, Mikhael Gilang P.P.P ${ }^{4}$, Agus Harno Nurdin Syah ${ }^{5}$ \\ 1,2,3,4,5 Pusat Teknologi Penerbangan, Lembaga Penerbangan dan Antariksa Nasional \\ Email Korespondensi: *Nur.mufidatul@lapan.go.id
}

Received: 13 Oktober 2020; Accepted : 28 Oktober 2020; Published : 1 November 2020

\begin{abstract}
ABSTRAK
Pengujian getaran terhadap head expander telah dilaksanakan. Pengujian ini bertujuan untuk mengetahui karakteristik dinamis dari head expander yang digunakan pada Laboratorium Uji Suhu dan Vibrasi Pusat Teknologi PenerbanganLAPAN. Head expander digunakan sebagai alat bantu pengujian untuk kebutuhan benda uji yang besar. Validasi head expander melalui metode eksperimental ini bertujuan untuk mengetahui tingkat homogenitas head expander. Pengambilan data menggunakan 4 buah akselerometer yang ditempatkan pada setiap ujung head expander. Getaran sine sweep diberikan mulai dari $5 \mathrm{~Hz}$ sampai $2000 \mathrm{~Hz}$ dengan amplitude konstan sebesar $1 \mathrm{~g}$ dan sweep rate sebesar 1 octave/minute. Hasil pengujian menunjukkan bahwa head expander memiliki sifat homogen dengan nilai frekuensi alami yang tidak berbeda jauh. Resonansi terjadi pada frekuensi $900 \mathrm{~Hz}, 1300 \mathrm{~Hz}, 1600 \mathrm{~Hz}$ dan $1900 \mathrm{~Hz}$. Nilai amplitudo terbesar dengan nilai 11,76 g terjadi pada frekuensi $1900 \mathrm{~Hz}$, sehingga head expander ini tidak dapat digunakan untuk pengujian diatas $1900 \mathrm{~Hz}$.
\end{abstract}

Kata Kuci : Head expander, Jig uji, Frekuensi alami, Getaran, Akselerometer.

\section{ABSTRACT}

Vibration testing of the head expander has been carried out. This test aims to determine the dynamic characteristics of the head expander that used in the Laboratory of Temperature and Vibration Testing. The Aeronautics TechnologyLAPAN. The Head expander is used as a testing tool for the needs of large specimens. Validation of the head expander through this experimental method aims to determine the level of homogeneity of the head expanders. Retrieval of data using 4 accelerometers that are placed at each end of the head expanders. Sine sweep vibrations are given from $5 \mathrm{~Hz}$ to $2000 \mathrm{~Hz}$ with a constant amplitude of $1 \mathrm{~g}$ and a sweep rate of 1 octave/minute. The test results show that the ends of the head expander have homogeneous properties with natural frequency values that do not differ much. Resonance occurs at a frequency of $900 \mathrm{~Hz}, 1300 \mathrm{~Hz}, 1600 \mathrm{~Hz}$ and $1900 \mathrm{~Hz}$. The largest amplitude value at 11,76 $\mathrm{g}$ occurs at a frequency of $1900 \mathrm{~Hz}$, so this head expander cannot be used for tests above $1900 \mathrm{~Hz}$.

Keyword: Head expander, Test fixture, Natural frequency, Vibration, Accelerometer.

\section{PENGANTAR}

Pengujian getaran merupakan sebuah pengujian yang dilakukan untuk mengetahui karakteristik dinamik dari sebuah struktur atau benda [1]. Selain untuk mengetahui karakteristik dinamik dari sebuah benda, pengujian getaran juga bisa digunakan untuk mengetahui kekuatan struktur saat dikenai getaran secara kontinyu [2]. Secara tidak langsung, getaran atau noise pada pesawat sangat berpengaruh pada perambatan tekanan dan retakan yang bisa mengakibatkan kerusakan atau kegagalan pada struktur pesawat [3] .Saat ini penelitian dan pengembangan pesawat tanpa awak maupun pesawat penumpang komersil masih terus dilakukan oleh Pusat Teknologi Penerbangan-LAPAN. Salah satu kegiatan pengembangan dan penelitian yang penting dilakukan dalam pengembangan pesawat adalah uji getaran. Seperti yang telah dilakukan pada penelitian-penelitian sebelumnya yang menunjukkan bahwa banyak kerusakan yang terjadi kepada setiap benda karena pengaruh adanya getaran. Kita telah ketahui bersama bahwa pesawat memiliki sumber-sumber getaran dimana ini akan berpengaruh pada kinerja pesawat itu sendiri. Sumber getaran utama pada pesawat ditimbulkan oleh sistem propulsi terutama saat pesawat melakukan lepas landas, termasuk saat penyalaan mesin dan steady state operation [4]. Sumber getaran lainya bisa ditimbulkan juga oleh sumber-sumber dari alam seperti getaran akibat turbulensi dan lain sebagainya [5].

Dengan mempertimbangkan beberapa struktur atau bagian pada pesawat yang memiliki ukuran lumayan besar, sedangkan ukuran dari armateur pada alat uji getaran hanya memiliki luasan yang terbatas maka perlu head expander tambahan untuk mengakomodir kebutuhan sampel yang besar tersebut. Head expander berfungsi sebagai tempat diletakkannya benda uji khususnya yang berukuran besar. Selain itu, head expander juga berfungsi untuk menyalurkan energi dalam bentuk getaran dari alat uji getaran ke benda uji [6]. Input getaran yang diberikan pada Head expander sebisa mengkin tidak berubah saat diteruskan pada benda uji, oleh karenanya Head expander haruslah sekaku mungkin sehingga tidak menyebabkan resonansi 
[1]. Head expander juga harus seringan mungkin karena semakin kaku dan semakin kecil massa sebuah benda maka frekuensi natural dari benda tersebut akan semakin besar [7]. Penggunaan head expander dalam pengujian haruslah divalidasi terlebih dahulu. Salah satu cara yang dilakukan untuk melakukan validasi sebuah head expander adalah dengan pengujian atau pengambilan data secara experimental. Pengujian sangat penting dilakukan untuk mengetahui level getaran pada permukaan head expander agar mendapatkan gambaran batas frekuensi pengujian yang diijinkan [8].

Pada pengujian head expander ada beberapa parameter yang perlu diketahui yakni frekuensi natural dan tingkat Homogenity head expander. Penelitian ini dilakukan untuk mengetahui dan memvalidasi performa dinamis dari Head expander yang telah dibuat. Verifikasi ini dilakukan agar peneliti memiliki gambaran mengenai rentang frekuensi serta batasan-batasan lainya yang bisa dilakukan dengan baik oleh head expnader yang ada di Laboratorium Suhu dan Vibrasi Pustekbang-LAPAN. Pada penelitian kali ini, validasi dilakukan terhadap sifat homogenitas head expander.Menjelaskan kronologis penelitian, meliputi desain penelitian, prosedur penelitian (dalam bentuk algoritma, pseudocode atau lainnya), cara pengujian dan perolehan data [1-3]. Uraian jalannya penelitian harus didukung referensi, sehingga penjelasannya dapat diterima secara ilmiah [2,4]. Tabel dan Gambar disajikan di tengah, seperti yang ditunjukkan di bawah ini dan dikutip dalam manuskrip.

\section{METODE PENELITIAN}

Proses Penelitian dan pengujian dilakukan di Laboratorium Suhu dan Vibrasi Pusat Teknologi Penerbangan, Lembaga Penerbangan dan Antariksa Nasional.

\subsection{Perangkat Pengujian}

\section{A. Shaker}

Dalam proses pengujian, Shaker yang digunakan diproduksi oleh ETS Solutions (Beijing) Ltd lihat pada gambar 1 (a) dengan spesifikasi teknis pada table 1 .

Tabel 1. Spesifikasi Shaker yang digunakan dalam penelitian [9]

\begin{tabular}{lclc}
\hline Type & M124M & Armature Material & Magnesium (M) \\
\hline Sine Force & $1.000 \mathrm{kgf}$ & Effective Armature Mass & $10 \mathrm{~kg}$ \\
Random Force & $1.000 \mathrm{kgf}$ & Load Attachment Points & M10 \\
Shock Force (6ms) & $2.000 \mathrm{kgf}$ & Armature Insert Pattern & $8 \mathrm{on} 100 \mathrm{~mm}$ \\
Useful Frequency Range & DC to $4.000 \mathrm{~Hz}$ & First Resonant Fre. $\pm 5 \%$, bare table & $8 \mathrm{on} 200 \mathrm{~mm}$ \\
Continuos Displacement & $51 \mathrm{~mm}$ & Max Static Payload & $3.600 \mathrm{~Hz}$ \\
Shock Displacement & $51 \mathrm{~mm}$ & Natural frequency thrust axis & $140 \mathrm{~kg}$ \\
Max Velocity (sine) & $1,8 \mathrm{~m} / \mathrm{s}$ & Stray Flux Density & $<5 \mathrm{~Hz}$ \\
Max Acceleration (sine) & $981 \mathrm{~m} / \mathrm{s} 2(100 \mathrm{~g})$ & Dimensions uncreated (WxDxH) & $1061 \times 730 \mathrm{~g} \mathrm{784} \mathrm{mm}$ \\
Armature Diameter & $240 \mathrm{~mm}$ & Shaker weight uncreated & $960 \mathrm{~kg}$ \\
\hline
\end{tabular}

B. Amplifier

Amplifier berfungsi sebagai sumber daya yang dibutuhkan untuk menggerakkan shaker. Dalam proses pengujian amplifier dan shaker haruslah kompatibel satu dengan yang lainnya agar tidak terjadi kerusakan. Amplifier yang digunakan di Laboratorium suhu dan vibrasi dibuat juga oleh ETS Solutions (Beijing) Ltd dengan nomor seri MPA403. Amplifier ini memiliki 3 buah sub-modul dengan rate power output sebesar $13 \mathrm{kVA}$, rate output voltage sebesar $120 \mathrm{Vrms}$ dan rated output current sebesar 108Arms. Amplifier memiliki berat sebesar $420 \mathrm{~kg}$ dengan dimensi 500x800x1850 (mm). Amplifier terdiri dari 1 filling cabinet seperti pada gambar $1(\mathrm{~b})$. 


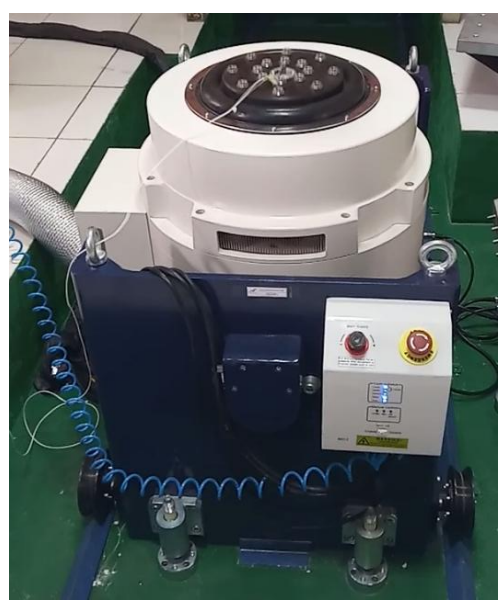

(a)

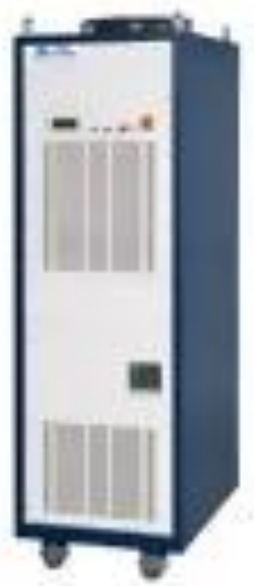

(b)

Gambar 1. (a) Shaker M124M, (b) Power Amplifier MPA403

\section{Kontroler dan sistem data akuisi}

Pada proses pengujian, Kontroler dan Sistem data akuisi yang digunakan adalah Vibration Research dengan tipe Medallion II VR9500. Kontroler dan sistem data akuisi ini memiliki 4 chanel dengan 1 channel digunakan sebagai kontroler dan 3 channel lainya digunakan sebagai input respon. Modul pengujian yang dapat digunakan pada kontroler dan sistem data akuisi ini berupa sinus, random, shock, sinus on random, sinus on sinus, random on random dan beberapa modul pengujian lain.

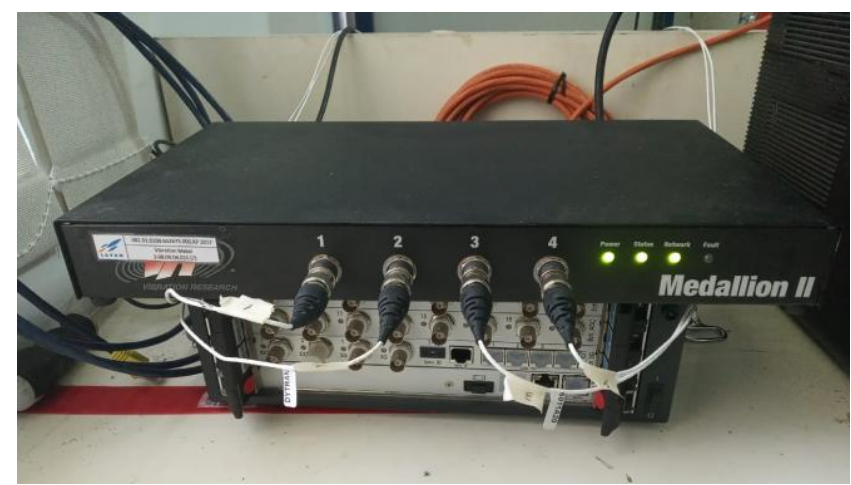

Gambar 2. Medallion II VR9500

D. Accelerometer

Sensor accelerometer yang digunakan pada saat pengujian merupakan produk dari SENZ dengan part number SZ3055B2. Sensor yang digunakan berjumlah 4 buah yang diletakkan pada ujung disetiap sisi-sisi Head expander. Sensor yang digunakan merupakan jenis sensor accelometer IEPE satu axis/satu arah. Dengan masing-masing sensor memiliki sensitivity sebesar $98,39 \mathrm{mV} / \mathrm{g}, 97,67 \mathrm{mV} / \mathrm{g}, 98,74 \mathrm{mV} / \mathrm{g}$, dan $97,14 \mathrm{mV} / \mathrm{g}$.

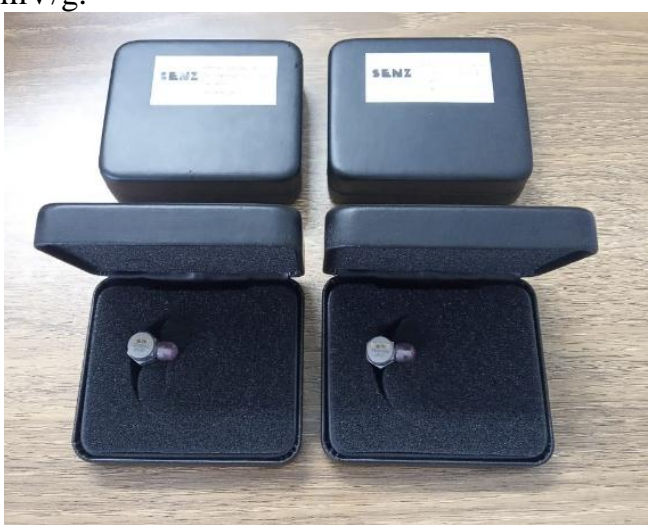

(a)

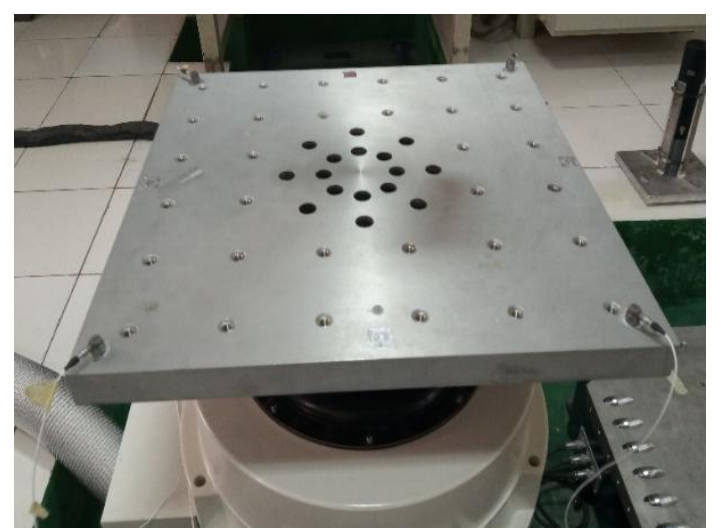

(b)

Gambar 3. (a) Accelerometer SENZ SZ3055B2, (b) Head expander dan peletakan akselerometer diatasnya 


\section{E. Head expander}

Head expander yang sedang dilakukan penelitian serta pengambilan data terbuat dari material alumunium (Al). Model Head expander adalah HE600SQA-240 dengan luasan atas sebesar 600 x $600 \mathrm{~mm}$. Berat dari head expander yang terdapat di laboratorium suhu dan vibrasi yakni $45 \mathrm{~kg}$. Berdasarkan klaim pabrikan, Range frekuensi yang bisa diterapkan pada HE ini adalah 5-2000 Hz. Penerapan frekuensi ini nantinya bergantung pada massa sampel uji yang akan diuji saat harus menggunakan HE ini.

\subsection{Pemodelan Fisis Pengujian}

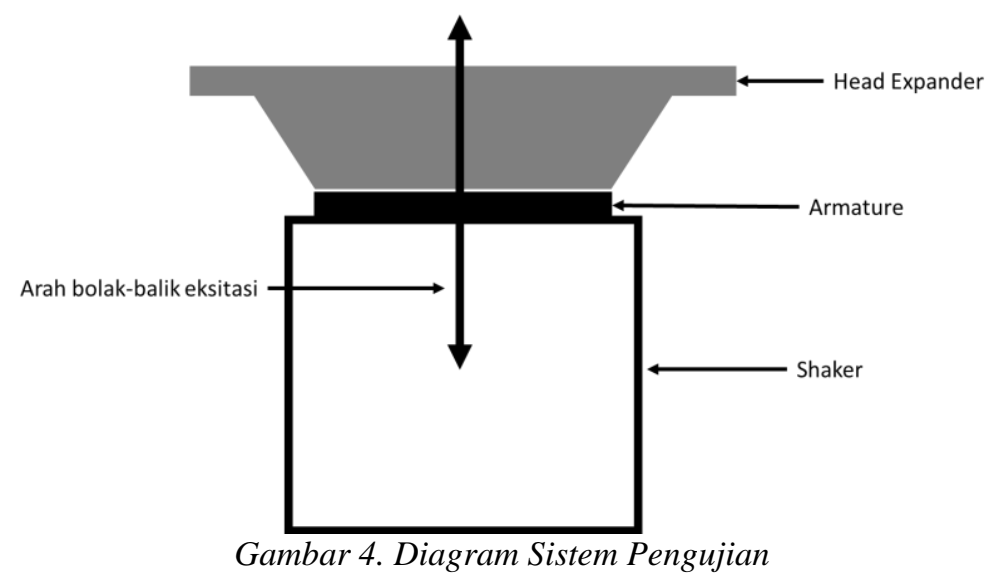

Head expander dipasangkan pada armature dari shaker menggunakan bolt dan diberi eksitasi naik-turun sebesar $1 \mathrm{G}$ seperti pada Gambar 4. Sambungan antara armature dengan head expander diasumsikan rigid sehingga permasalahan dapat disederhanakan menjadi sistem gerak satu derajat kebebasan dengan kondisi batas fixed pada bagian dasar seperti yang digambarkan pada Gambar 5 . Dimana $\mathrm{M}$ adalah massa, $\mathrm{K}$ adalah modus kekakuan, $\mathrm{C}$ adalah keofisien redam dan $\mathrm{F}$ adalah gaya, serta $\mathrm{y}$ adalah perpindahan arah pada sumbu $y$.

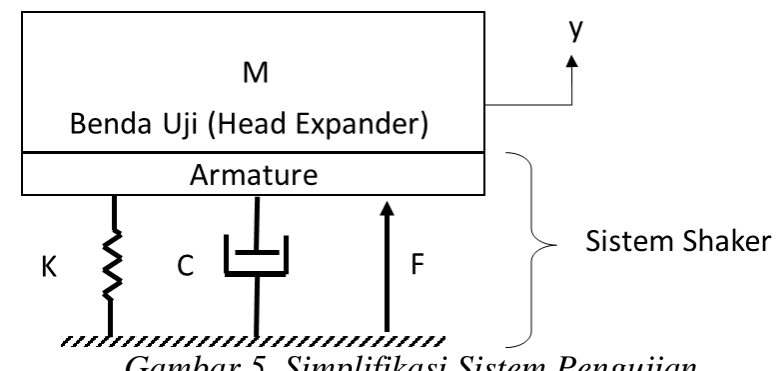

Persamaan kesetimbangan gerak sebuah sistem pada gambar 5 dapat dituliskan dalam bentuk matematis sebagai berikut:

$$
M \ddot{y}+C \dot{y}+K y=F(t)
$$

Shaker memberi eksitasi dengan amplitudo $F_{A}$ dan frekuensi $\Omega$

$$
F(t)=F_{A} \sin \Omega t
$$

Sehingga persamaan kesetimbangan dapat ditulis ulang sebagai berikut:

$$
M \ddot{y}+C \dot{y}+K y=F_{A} \sin \Omega t
$$

Sehingga solusinya dapat diperoleh dengan dalam bentuk

$$
y=B \sin \Omega t+C \cos \Omega t
$$

Setelah disubsitusikan pada persamaan kesetimbangan (4) sehingga diperoleh persamaan untuk B dan C sebagai berikut:

$$
\begin{aligned}
& B=\frac{\left(\omega^{2}-\Omega^{2}\right)\left(F_{A} / m\right)}{\left(\omega^{2}-\Omega^{2}\right)^{2}+4 \omega^{2} \Omega^{2} \zeta^{2}} \\
& C=\frac{-2 \omega \Omega \zeta\left(F_{A} / m\right)}{\left(\omega^{2}-\Omega^{2}\right)^{2}+4 \omega^{2} \Omega^{2} \zeta^{2}}
\end{aligned}
$$


Dengan $\omega$ adalah frekuensi natural dan $\xi$ adalah koefisien redaman. Benda uji yang dieksitasi akan mengeluarkan gaya respon terhadap fungsi waktu $\mathrm{R}(\mathrm{t})$ yang secara matematis dituliskan sebagai berikut:

Dengan amplitudo respon $R_{A}$ :

$$
R(t)=R_{A} \sin (\Omega t-\phi)
$$

$$
R_{A}=\frac{\left(F_{A} / k\right)}{\left\{\left[1-(\Omega / \omega)^{2}\right]^{2}+4 \zeta^{2}(\Omega / \omega)^{2}\right\}^{1 / 2}}
$$

dan pergeseran fasa $\phi$ diperoleh dari:

$$
\tan \phi=\frac{2 \zeta(\Omega / \omega)}{1-(\Omega / \omega)^{2}}
$$

Amplitudo respon $R_{A}$ dapat ditulis dalam bentuk factor magnifikasi M sebagai berikut:

dengan faktor magnifikasi M:

$$
R_{A}=M\left(F_{A} / k\right)
$$

$$
M=\frac{1}{\left\{\left[1-(\Omega / \omega)^{2}\right]^{2}+4 \zeta^{2}(\Omega / \omega)^{2}\right\}^{1 / 2}}
$$

Faktor magnifikasi adalah sebuah faktor yang menggambarkan rasio antara amplitudo gaya respon dengan amplitudo gaya eksitasi. Apabila redaman diperhitungkan, maka akan terjadi pergeseran fasa atau delay. Pergeseran fasa menyebabkan fasa gaya eksitasi yang diterima oleh benda uji berbeda dengan fasa gaya eksitasi dari shaker. Gaya yang sampai ke benda uji karena keberadaan peredam $\mathrm{P}(\mathrm{t})$ dapat diformulasikan sebagai berikut:

Dengan amplitudo $P_{A}$

$$
P(t)=P_{A} \sin (\Omega t-\phi+\delta)
$$

$$
P_{A}=T F_{A}
$$

Nilai transmissibility (T) secara matematis bisa dituliskan sebagai berikut [10]:

$$
T=\left\{\frac{1+(2 \zeta \Omega / \omega)^{2}}{\left[1-(\Omega / \omega)^{2}\right]^{2}+[2 \zeta(\Omega / \omega)]^{2}}\right\}^{1 / 2}
$$

Dengan nilai pergeseran fasa akibat redaman dapat diperoleh dari persamaan berikut:

$$
\tan \delta=2 \zeta \Omega / \omega
$$

\subsection{Proses pengujian}

Metodologi yang digunakan dalam penelitian ini adalah metode eksperimen dengan melakukan pengujian dan pengambilan data pada head expander yang diberi perlakuan getaran. Pengujian head expander dilakukan untuk mengetahui karakteristik dinamisnya berupa nilai dari frekuensi alaminya dan sifat kehomogenitasnya. Nilai frekuensi alami dari head expander harus diatas dari rentang nilai frekuensi yang digunakan untuk pengujian. Jenis uji getaran yang dilakukan adalah sine sweep. Getaran sine sweep yang diberikan dimulai dari frekuensi $5 \mathrm{~Hz}$ sampai $2000 \mathrm{~Hz}$ sesuai dengan klaim pabrikan terkait kemampuan head expander dengan amplitudo yang konstan sebesar 1g. Nilai dari sweep rate yang diberikan yaitu sebesar 1 octave/minute.

Selama pengujian besarnya getaran yang terjadi pada head expander diukur menggunakan 4 sensor accelerometer yang diletakkan masing-masing di ujung head expander. 1 akselerometer digunakan sebagai kontrol dan tiga lainya digunakan sebagai sinyal respon. Posisi sensor yang dijadikan sebagai kontrol dibuat 4 variasi untuk mengetahui sifat kehomogenitasan pada head expander tersebut. Head expander bersifat homogenitas jika pada saat posisi sensor yang dijadikan sebagai kontrol dipindah pindah maka nilai frekuensi alaminya masih tetap pada rentang yang sama atau terjadi perubahan yang tidak terlalu besar. Peletakan accelerometer dapat dilihat pada gambar 4 .

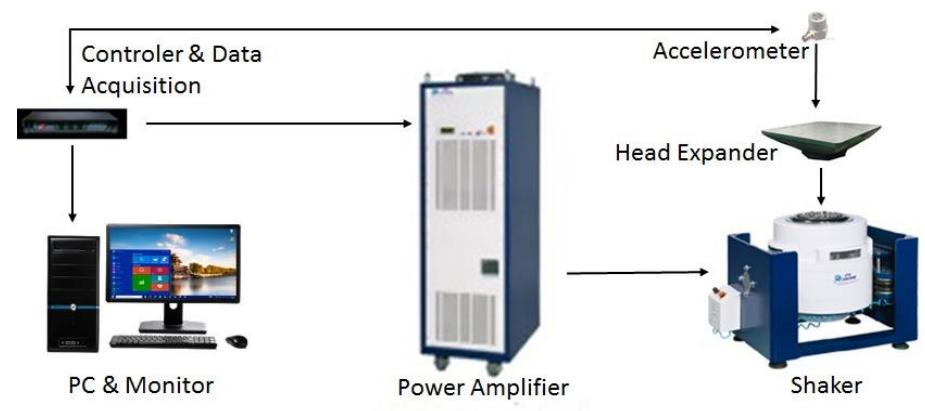

Gambar 5. Skema pengujian HE di Laboratorium Suhu dan Vibrasi Pustekbang-LAPAN 
Nilai getaran ditampilkan pada grafik dengan menggunakan domain frekuensi untuk memudahkan pembacaan atau penentuan dari nilai frekuensi alami. Penentuan nilai frekuensi alami salah satunya dengan berdasar pada nilai transmissibility atau perbandingan antara respon frekuensi terhadap frekuensi input. Nilai transmibility saat terjadinya frekuensi alami adalah lebih dari atau sama dengan dua.

\section{HASIL DAN PEMBAHASAN}

Dari hasil pegujian yang telah dilakukan terhadap head expander didapatkan data berupa percepatan pada domain frekuensi. Berdasarkan data tersebut dapat diketahui nilai frekuensi alami head expander. Grafik hasil pengujian bisa dilihat pada gambar 6 serta nilai frekuensi alami untuk masing-masing chanel sebagai kontrol bisa dilihat pada tabel 2 .

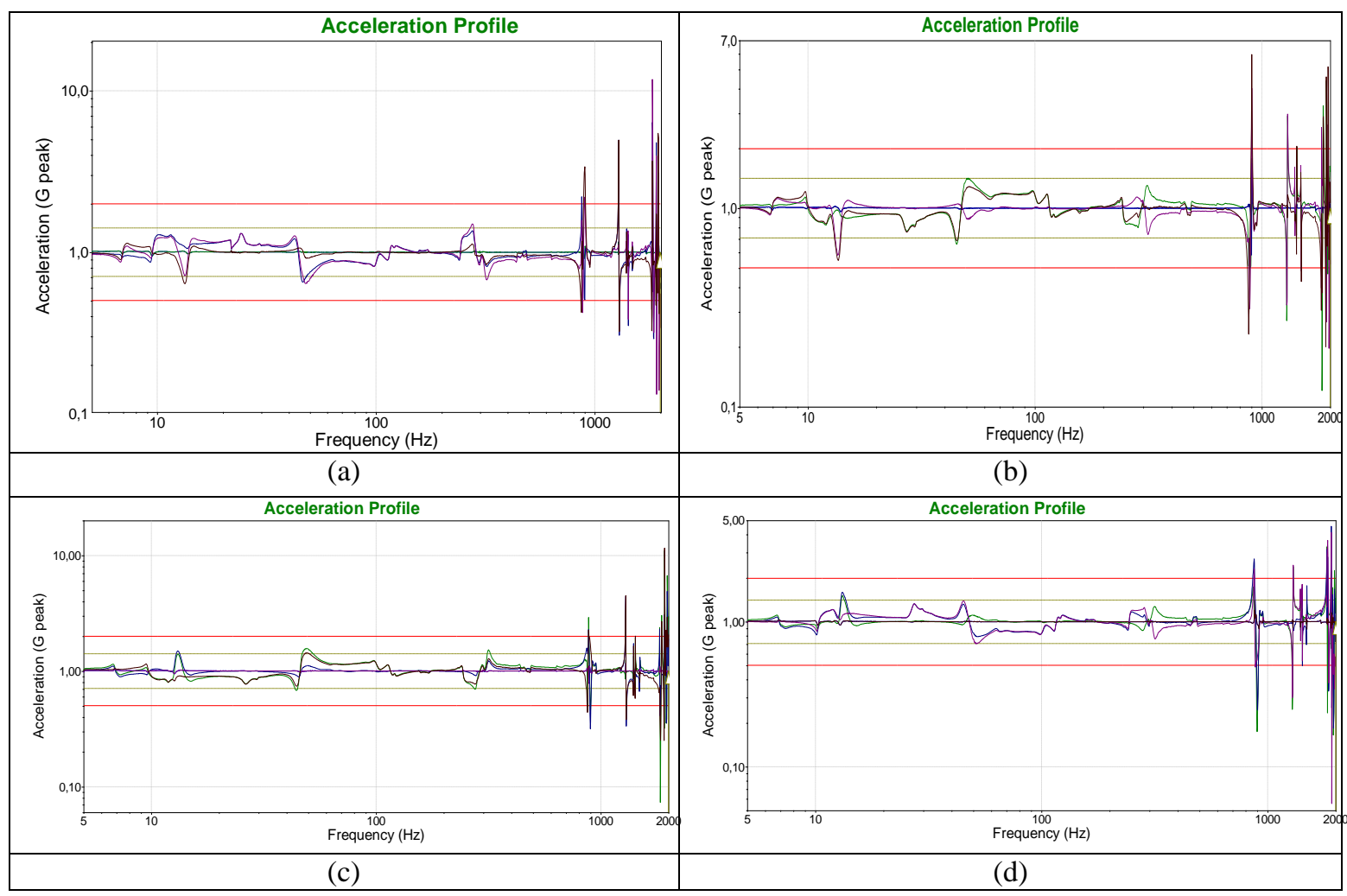

Gambar 6. Grafik hasil pengujian sine sweep dengan (a) channel 1 sebagai kontrol (b) channel 2 sebagai kontrol (c) channel 3 sebagai kontrol (d) channel 4 sebagai kontrol.

Pada gambar diatas, grafik berwarna hiju merupakan grafik untuk channel 1, warna biru untuk channel 2, warna ungu untuk channel 3 dan warna hitam untuk channel 4. Grafik menunjukkan bahwa pada frekuensi tertentu terdapat puncak-puncak grafik yang lebih tinggi dari sebelum atau sesudahnya. Puncak tersebut dapat dikatakan nilai frekuensi alami dengan syarat nilai transmisisbility melebihi 2. Dengan melakukan variasi posisi kontrol didapat nilai frekuensi alaminya menunjukkan bahwa perbedaanya tidak terlalu jauh dan seragam. Kondisi ini menunjukkan bahwa antar ujung sisi luar Head expander memiliki nilai homogenitas yang baik.

Pada grafik terlihat bahwa besar amplitude untuk masing-masing frekuensi natural memiliki nilai yang berbeda. Dengan membuat variasi lokasi penempatan sensor sebagai kontrol didapatkan bahwa frekuensi alami terjadi pada $900 \mathrm{~Hz}, 1300 \mathrm{~Hz}$ dan $1900 \mathrm{~Hz}$. Pada saat sensor 1 dijadikan kontrol, puncak grafik tertinggi didapatkan pada frekuensi 1839 dengan amplitudo sebesar 11,76 g. Puncak grafik tersebut yang merupakan respon dari sensor 3. Pada saat sensor 2 dijadikan kontrol, puncak grafik tertinggi didapatkan pada frekuensi 1958 dengan amplitudo sebesar 5,158 g. Puncak grafik tersebut yang merupakan respon dari sensor 4. Pada saat sensor 3 dijadikan kontrol, puncak grafik tertinggi didapatkan pada frekuensi 1924 dengan amplitudo sebesar 11,57 g. Puncak grafik tersebut yang merupakan respon dari sensor 4. Pada saat sensor 4 dijadikan kontrol, puncak grafik tertinggi didapatkan pada frekuensi 1912 dengan amplitudo sebesar 4,55 g. Puncak grafik tersebut yang merupakan respon dari sensor 3. 
Dynamical Characteristics of a Head Expander for Vibration Testing In Pustekbang Laboratory

Tabel 2. Data percepatan domain frekuensi Head expander

\begin{tabular}{|c|c|c|c|c|c|c|c|c|c|c|}
\hline \multirow[b]{2}{*}{ No } & \multirow{2}{*}{$\begin{array}{l}\text { Channel } \\
\text { Kontrol }\end{array}$} & \multirow{2}{*}{$\begin{array}{l}\text { Channel } \\
\text { Respon }\end{array}$} & \multicolumn{2}{|c|}{ Frekuensi alami 1} & \multicolumn{2}{|c|}{ Frekuensi alami 2} & \multicolumn{2}{|c|}{ Frekuensi alami 3} & \multicolumn{2}{|c|}{ Frekuensi alami 4} \\
\hline & & & $\mathrm{F}(\mathrm{Hz})$ & $\mathrm{A}(\mathrm{g})$ & $\mathrm{F}(\mathrm{Hz})$ & A (g) & $\mathrm{F}(\mathrm{Hz})$ & $\mathrm{A}(\mathrm{g})$ & $\mathrm{F}(\mathrm{Hz})$ & $\mathrm{A}(\mathrm{g})$ \\
\hline \multirow{4}{*}{1} & \multirow{3}{*}{ Ch 1} & Ch 2 & 874.5 & 2.203 & 1,291 & 4.952 & 1,839 & 6.363 & 1,918 & 4.782 \\
\hline & & Ch 3 & 901.1 & 2.192 & 1,839 & 11.760 & 1,918 & 3.945 & 1,964 & 3.097 \\
\hline & & $\mathrm{Ch} 4$ & 901.1 & 3.38 & 1,291 & 4.95 & 1,839 & 3.667 & 1,953 & 5.463 \\
\hline & \multirow{3}{*}{ Ch 2} & Ch 1 & 903.8 & 1.777 & 1,299 & 2.91 & 1,861 & 3.288 & 1,924 & 4.384 \\
\hline \multirow{2}{*}{2} & & Ch 3 & 903.8 & 4.015 & 1,299 & 2.983 & 1,834 & 2.545 & 1,958 & 2.635 \\
\hline & & Ch 4 & 901.1 & 4.102 & 1,861 & 2.843 & 1,924 & 4.591 & 1,958 & 5.158 \\
\hline \multirow{4}{*}{3} & \multirow{3}{*}{ Ch 3} & Ch 1 & 882.4 & 2.905 & 1,828 & 2.375 & 1,867 & 3.027 & 1,924 & 10.97 \\
\hline & & Ch 2 & 882.4 & 2.281 & 1,291 & 4.457 & 1,828 & 2.309 & 1,924 & 3.076 \\
\hline & & Ch 4 & 882.4 & 2.253 & 1,867 & 2.681 & 1,924 & 11.57 & 1,976 & 2.924 \\
\hline & & Ch 1 & 1,299 & 2.405 & 1,828 & 3.287 & 1,912 & 2.249 & & \\
\hline \multirow{2}{*}{4} & $\mathrm{Ch} 4$ & Ch 2 & 871.9 & 2.714 & 1,828 & 3.149 & 1,912 & 4.55 & & \\
\hline & & Ch 3 & 871.9 & 2.305 & 1,299 & 2.453 & 1,845 & 3.641 & 1,912 & 4.117 \\
\hline
\end{tabular}

Dari hasil tersebut menunjukkan bahwa hasil eksperimental dengan klaim pabrikan memiliki nilai yang mendekati. Transmisibility pada head expander memiliki nilai yang baik, ini menandakan bahwa head expander memiliki homogenitas yang baik meskipun lebih rendah $100 \mathrm{~Hz}$ dibandingkan klaim pabrikan dengan posisi sensor sebagai kontrol yang disarankan adalah pada posisi 2 dan 4 . Untuk penelitian selanjutnya perlu dilakukan modifikasi lebih lanjut agar head expander memiliki nilai frekuensi alami yang lebih tinggi dengaan nilai amplitudo yang lebih kecil. Menambah kekakuan dan mengurangi massa dari head expander mampu menaikan frekuensi naturalnya. Namun, mengurangi amplitudo secara paksa akan mengurangi respon pada resonansi dan akan berdampak pada nilai transmisibility[11].

\section{KESIMPULAN}

Pada pengujian head expander dengan diuji getar menggunakan sine sweep didapatkan frekuensi alaminya terjadi di sekitar frekuensi $900 \mathrm{~Hz}, 1300 \mathrm{~Hz}$ dan $1900 \mathrm{~Hz}$. Dengan dilakukan variasi sebanyak 4 lokasi untuk sensor kontrol menghasilkan nilai frekuensi alami yang hampir sama sehingga head expander tersebut memiliki sifat yang homogen. Pada frekuensi disekitar $1900 \mathrm{~Hz}$ terjadi puncak getaran dengan amplitude yang sangat tinggi mencapai 11,76 g, sehingga dapat disimpulkan head expander ini dapat digunakan untuk pengujian getaran dengan rentang frekuensi dibawah $1900 \mathrm{~Hz}$.

\section{DAFTAR PUSTAKA}

[1] E. De Barros and C. D. A. Souto, "Evaluation of a vibration text fixture," Int. J. Acoust. Vib., 2017.

[2] H. S. Jeong and J. R. Cho, "Optimal design of head expander for a lightweight and high frequency vibration shaker,” Int. J. Precis. Eng. Manuf., 2016.

[3] S. Fábry and M. Češkovič, "Aircraft gas turbine engine vibration diagnostics," MAD - Mag. Aviat. Dev., vol. 5, pp. 24-28, 2017.

[4] S. Kumar, N. Kumar, and R. Kumar, "Vibration Mapping of Head Expander for 9000 Kgf Shaker," J. Emerg. Technol. Innov. Res., vol. 6, no. 6, pp. 280-284, 2019.

[5] A. Y. Zverev, "Noise control mechanisms of inside aircraft," Acoust. Phys., vol. 62, no. No.4, pp. 478-482, 2016.

[6] H. Luo, C. Yu, T. Wu, and H. Wang, "Structure design and dynamic characteristic analysis of vibration fixture," in Proceedings of 2018 IEEE International Conference on Mechatronics and Automation, ICMA 2018, 2018.

[7] W. X. Shen, W. S. Ma, and L. W. Zhang, "Research on the design of fixture for motor vibration test," in IOP Conference Series: Materials Science and Engineering, 2018.

[8] Bruel\&Kjaer, "Vibration Testing," Denmark.

[9] E. Solution, Operating and Maintenance Manual (Medium Force Series). China, 2019.

[10] A. Parkinson, R. Armsond, D. Cooknell, J. Dixon, M. Keith, and R. Morgan, "Engineering Mechanics : Solids," in Technology a second level course, 1.1., Yorkshire,: H. Charlesworth of Huddersfield, 1990, pp. 24-30.

[11] J. Dewanto, "Kajian Teoritik Sistem Peredam Getaran Satu Derajat Kebebasan," J. Tek. Mesin, vol. 1, no. 2, pp. $156-162,1999$. 
